\title{
A Simple Sack-holding Frame
}

\section{J.A. HANSMIRE, C.M. BRITTON, AND S.S. WALLER}

\begin{abstract}
A lightweight frame was designed to hold sacks when sampling vegetation by species. Sacks are attached with clips to a pegboard in an organized arrangement with labels that are easily read. The frame is especially useful on windy days.

Harvesting rangeland vegetation by species is a common practice in range research. Weight be species is a valuable meaurement in many plant communities. Once clipped, individual species or groups of species are placed in paper sacks, then dried and weighed. As the number of sacks per quadrat increase, their management in the field becomes more difficult. A lightweight sack frame was designed to hold sacks in an organized arrangement such that identifying labels could be easily read (Fig. 1). This minimizes time spent searching for the proper sack. The frame is especially useful on windy days and is easily transported.

The frame was constructed to handle different numbers of sacks within easy reach of the clipper. The illustrated frame can hold 21 , No. 12 sacks. Sacks are attached by clips and arranged on 3 rows of pegboard. The pegboard allowed clips to be adjusted for different sack sizes. The frame can be adapted to meet criteria of individual projects.

\footnotetext{
Authors are graduate fellow in Department of Range and Wildlife Management, Texas Tech University, Lubbock and Welder Wildlife Foundation, Sinton, Texas; associate professor, Department of Range and Wildlife Management, Texas Tech University, Lubbock; and associate professor, Department of Agronomy (Range Management), University of Nebraska, Lincoln. This is a contribution of the College of Agricultural Sciences, Texas Tech University, No. T-9-311, and Rob and Bessie Welder Wildlife Foundation Contribution No. 273.

The authors wish to express their appreciation to Wayne W. Seipp for his help in constructing the sack frame.

Manuscript received October 25, 1982
}

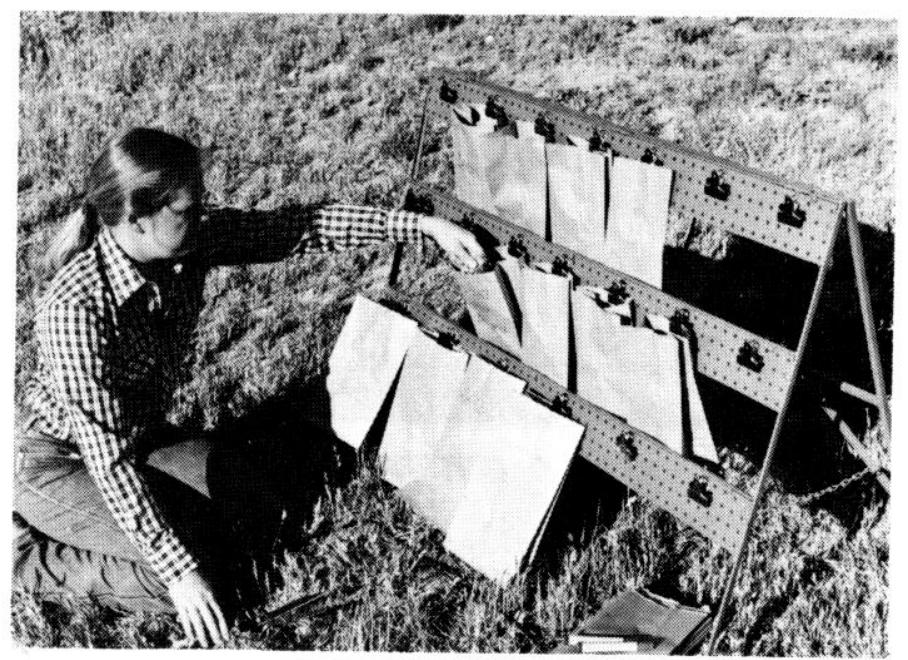

Fig. 1. Sack-holding frame, made with angle iron and pegboard, holds and organizes sacks.

To construct the frame, 3 cross-braces (120 cm length) were welded to the front legs $(90 \mathrm{~cm}$ tall) and 2 cross-braces were welded to the back legs. Angle iron $(0.64 \mathrm{~cm})$ was used; however, aluminum material also would be suitable. Pegboard ( 10 by 118 $\mathrm{cm}$ ) was bolted on the inside edge of the angle iron. A distance of 16 $\mathrm{cm}$ was allowed between the pegboard strips to permit sacks to fall behind the pegboard. Height above the ground to the bottom pegboard was determined by sack length $(28 \mathrm{~cm}$ in this case). The front and back sides were joined by hinges welded at the top. A lightweight chain was fastened between the front and back legs. The cost was approximately $\$ 20.00$. 